SERI/TP-211-1889

UC Category: 60

\title{
Research Results for the Tornado Wind Energy System: Analysis and Conclusions
}

Eric Jacobs

January 1983

Presented at the ASME Solar Energy Division 6th Annual Technical Conference Orlando, Florida

19-21 April 1983

Prepared Under Task No. 1067.10

WPA No. 171

Solar Energy Research Institute

A Division of Midwest Research Institute

1617 Cole Boulevard

Golden, Colorado 80401

Prepared for the

U.S. Department of Energy

Contract No. EG-77-C-01-4042 


\author{
Printed in the United States of America \\ Available from: \\ National Technical Information Service \\ U.S. Department of Commerce \\ 5285 Port Royal Road \\ Springfield, VA 22161 \\ Price: \\ Microfiche $\$ 3.00$ \\ Printed Copy $\$ 4.00$
}

\begin{abstract}
NOTICE
This report was prepared as an account of work sponsored by the United States Government. Neither the United States nor the United States Department of Energy, nor any of their employees, nor any of their contractors, subcontractors, or their employees, makes any warranty, express or implied, or assumes any legal liability or responsibility for the accuracy, completeness or usefulness of any information, apparatus, product or process disclosed, or represents that its use would not infringe privately owned rights.
\end{abstract}




\section{RESEARCH RESULTS FOR THE TORNADO}

WIND ENERGY SYSTEM:

ANALYSIS AND CONCLUSIONS

Eric Jacobs*

\section{ABSTRACT}

The Tornado Wind Energy System (TWES) concept utilizes a wind driven vortex coniined by a hollow tower to create a low pressure core intended to serve as a turbine exhaust reservoir. The turbine inlet flow is orovided by a separate ram air supply. Numerous experimental and analytical research efforts have investigated the potential of the TWES as a wind energy conversion system (WECS). The present paper summarizes and analyzes much of the research to date on the TiNES. A simplified cost analysis incorporating these research results is also included. Based on these analyses, the TiNES does not show significant promise of improving on either the periormance or the cost of energy attainable by conventional WECS. The prospects for achieving either a system power coefficient above 0.20 or a cost of energy less than $50.50 / \mathrm{kWh}$ ( 1979 dollars) appear to be poor.

\section{NOMENCLATURE}

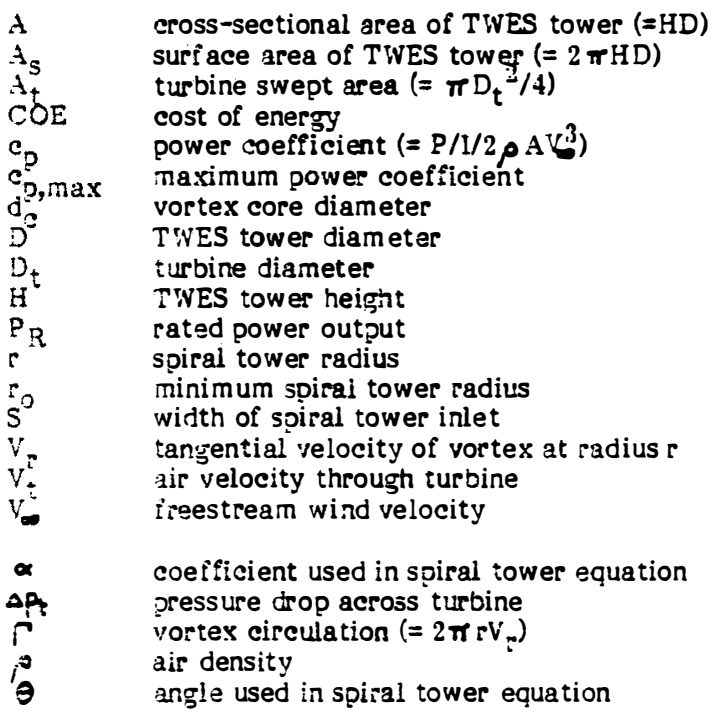

\section{INTRODUCTIDN}

The Tornado Wind Energy System (T'NES) vas proposed by J.T. Yen of the Grumman ierospace Corp. [1]. The TiVES concept entrains ambient winds to generate a vortex within a hollow tower. The vortex core then serves as a low pressure e:chaust reservoir for a vertical axis oropeller-type turbine located at the jottom oi the tower. The turjine inlet air is jroviced by a separate ram air supply.

$A$ jketch of the originally proposed tower configuration is shown in Eigure 1. This soiral shaped iower has been oresumed to provide the naximum periormance artainable bv $\rightarrow$ TrVES. However, the soiral contiguration is irherently inpractical for large TVES as it would require unidirectional

* Associate Vemoer, ASME
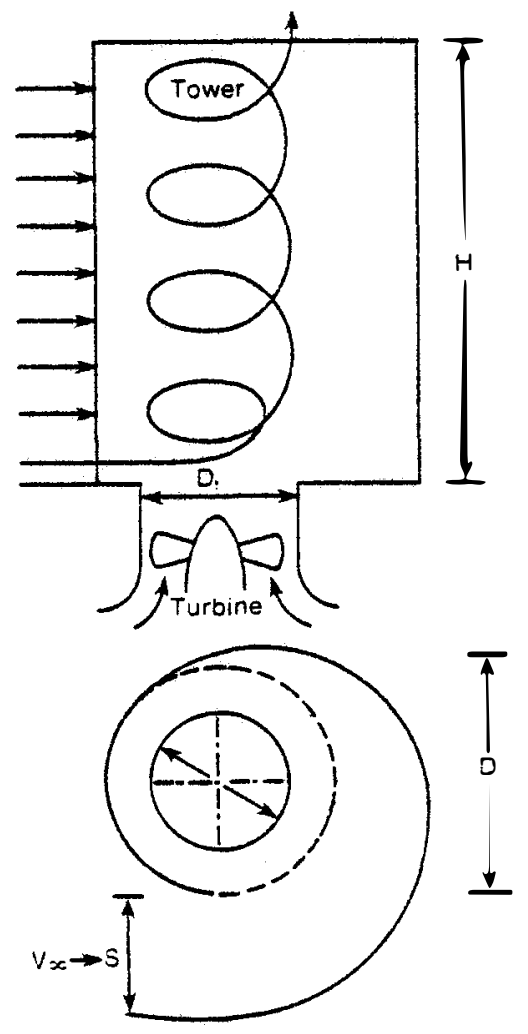

Figure 1. Sketch of a Model for the TornadoType Wind Energy System. Spiral Tower Configuration

winds. Thus the omni-directional, fixed multi-vane tower configuration, such as shown in Figure 2, has jeen used for many of the more recent studies. However, the spiral tower configuration remains useful in ascertaining upper limits for potential TWES pericrmance.

Several experimental and enalvtical research efforts have investigated the potential of ine TWES as a wind energy conversion syst $\mathrm{m}$ (iNECS). The sresent paper summarizes and analyzes nuch of the resegren to date on the TivES. Detailed aralysis of these research resuits provides several broadly supported conciusions regarding prospestive T'VES performance. As cost $0 i$. ənergy is generally the bottom line in evaluating a iVECS, a simplifited cost analysis of the TiVES is also oresented to further delineata the potentiai di the T'vES for cost competitive wino energy conversion.

\section{EXPEPIMENTAL INVESTIGATTON OE THE TINES}

Several experimental investigations of ine TiVES iave been periormed. including those by Yen [2,j, Miller et aj it, 


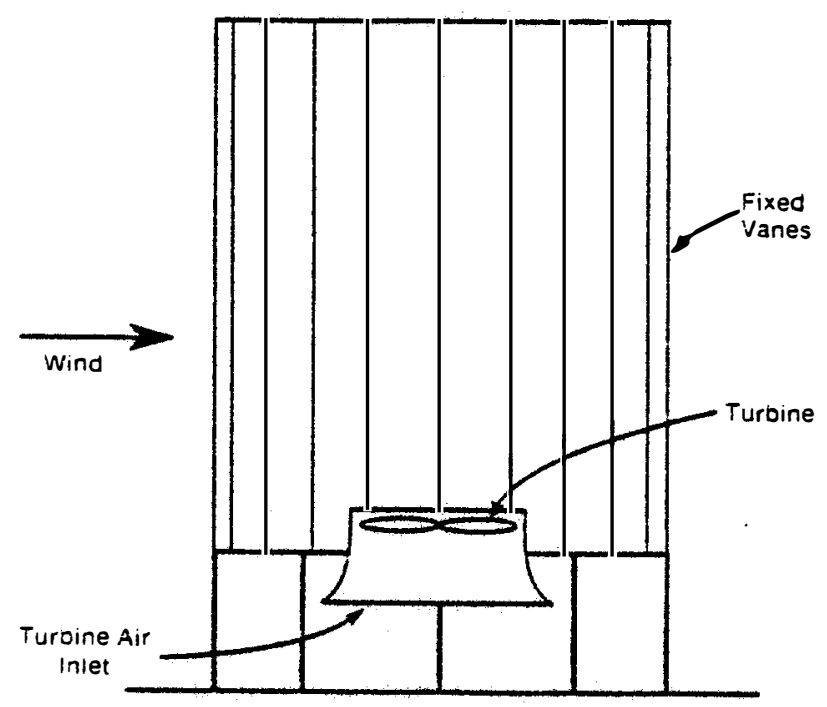

Figure 2. Sketch of the Omnidirectional Multi-Vane TWES

Windrich et al [5], and Hsu and Ide [6]. These investigations have utilized both the spiral and multi-vane configurations for the TWES, and have studied the effects of several parameters, e.g., tower height-to-diameter ratio (H/D) and turbine-to-tower diameter ratio $\left(D_{t} / D\right)$, on system performance. The results of these research efforts provide substantial indications of the potential of the TWES as a wind energy conversion system (WECS).

All of the power coefficients reported by these studies have been based on the frontal area HD of the T'NES tower, i.e.

$$
C_{p}=\frac{\Delta D_{t} V_{t} A_{t}}{1 / 2 \rho V_{\omega D}^{3}}
$$

For the spiral tower configuration, $D$ is defined as in Figure 3 and does not include the width of the tower inlet. Use of the total cross-sectional area $\mathrm{H}(\mathrm{D}+\mathrm{S})$, or

$$
C_{0}=\frac{\Delta p_{t} v_{t} A_{t}}{1 / 2 \rho v_{\omega}^{3} H(D+s)}
$$

:vould provide power coefficients better suited for comparisons with conventional horizontal and vertical axis 'vind turbines as well as with similar TWES configurations. Similarly, use of system power coeificients which include turbine, transmission, and generator losses would also provide more equivalent bases for performance comọarisons. Such losses would presumably total at least $\mathbf{2 0 \%}$. However, unless otherwise stated. power coefficients present hersin for the soirai tower configuration are based on the original detinition of tower frontal area $\mathrm{RD}$ and the power avaiiable to the turbine as in Eccuation (1). All power coefficients presented for the multi-yane tower configuration are also based on Equation (1) with $\mathrm{D}$ defined as ivice the mean radius of the vanes from the tower axis.

\section{The Exoerimental Setups: Discussion and C.omments}

Discussions of the TivES experiments periormed Jy Yen [2.3], Viller et al. [4], ,Vindricn ta $a i .[5]$, and Hisu and Ide [6] are presented below. Of particular importance are any acoparent experimentai errors and uncertainties vinich signilicantly ivegken the results and conclusions obtained during trese

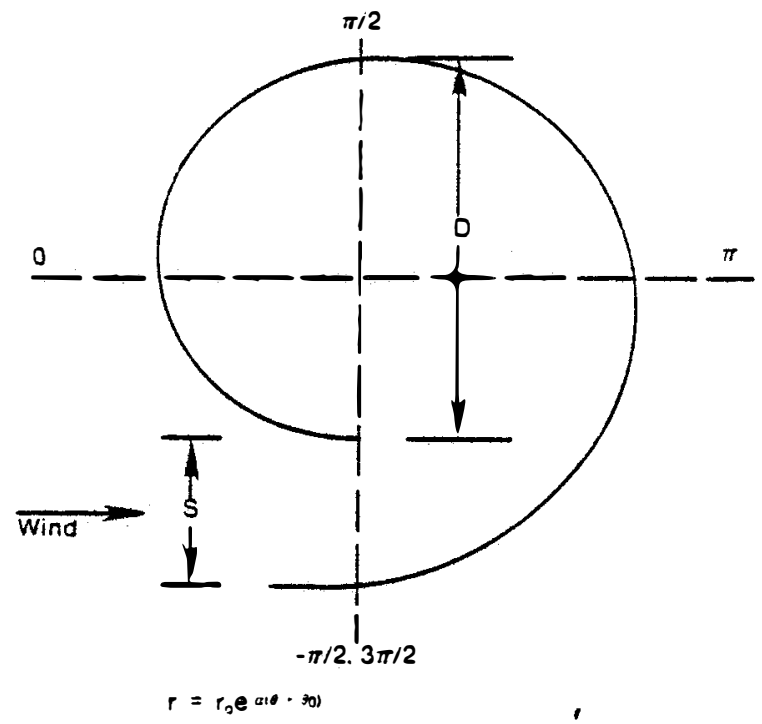

Figure 3. Top View of TWES Spiral Tower
Configuration

investigations. Any use of the reported results should be tempered by an awareness of these errors and uncertainties.

\section{The Yen Experiments}

Extensi ve research of the T'NES has been periormed iv J.T. Yen of the Grumman Aerospace Corporation [2,3]. The U.S. Federal Wind Energy Program supported two phases of the research during the periods of September 197 $\hat{j}$ through February 1978 and September 1978 through April 1980. Support has also been provided by the New York State Energy Research and Development Authority (NYS-ERDA). The initial research phase included an experimental study of two small node!s based upon the unidirectional spiral towe: configuration [2]. The spiral shape is given by

$$
r=i_{0} e^{\alpha\left(\vartheta+\theta_{0}\right)}
$$

where $\theta$ is defined as in Figure 3 with $\theta_{0}=\pi / 2$ and, for the Yen spiral tower models, $\alpha=0.129$. The chosen tow ar diameters (D) vere $12.7 \mathrm{~cm}(5 \mathrm{in})$ and $25.4 \mathrm{~cm}$ (10 in), corresponding to $r_{2}=5 \mathrm{~cm}(2 \mathrm{in})$ and $r_{0}=10 \mathrm{~cm}(t i n)$, resoectively. The total spiral tower cross-sectional area $\mathrm{H}(\mathrm{D}+\mathrm{S})$ is l.jHD for the Yen models. A schematic of the experimentai setw used by Yen for the soiral tower nodeis is shown in Figure 4. The tests $v$ ere concucted in the $2.1 \mathrm{~m}$. $3.0 \mathrm{n}(\mathrm{ft} \mathrm{x} 10 \mathrm{ft})$ Grumman Low Speed Wind Tunnel with this setup for both screen-simulater and blaced turbines. Severa! parameter aifecting TiVES performance vere stucied. including tower height-to-diameter ratio ( tower diameter ratio $\left(D_{t^{\prime}}{ }^{\prime} D\right)$, and system size.

During the second phase of Federaliy funded research on the TiveS oy Grumman terospace Curp., in onnidirectional iixed muiti-yane tower was iested ind. is with the sorrai tower, two small nodels of the muiti-vane configucation. having Jiametes $D=25.4 \mathrm{~cm}(10 \mathrm{in})$ and $D=50.3 \mathrm{~cm}(20 \mathrm{in})$ rospectivelv, were vind iunnel tested 0 ascertain sotential rives periormance. Tos and side views oi the omni- 


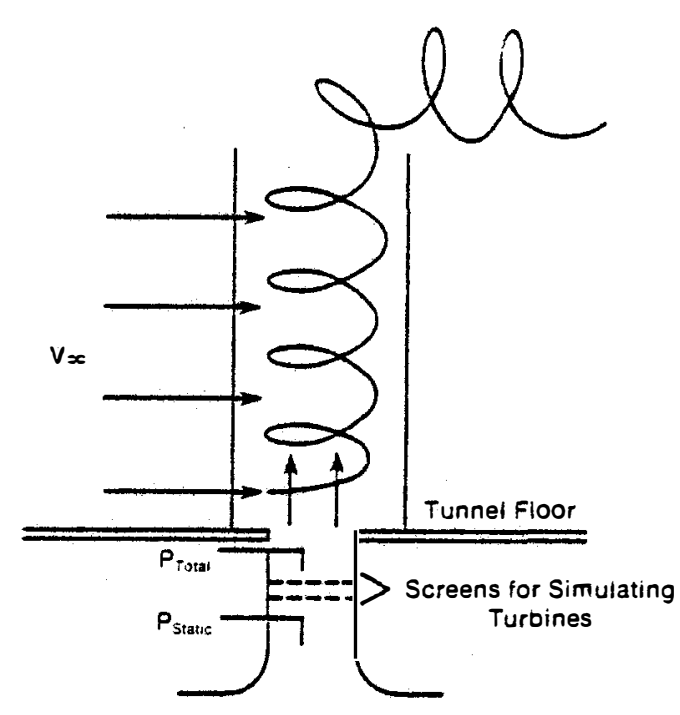

Figure 4. Experimental Setup with Screen-Simulated Turbine, Yen Spiral Tower TWES Model [from Ref. 2]

directional multi-vane tower models are shown in Figures 5 and $b$ respectively. The tests were conducted in both the $1.2 \mathrm{~m} \times 1.8 \mathrm{~m}$ ( 4 it $\times 6 \mathrm{ft}$ ) Grumman Research and the $4.25 \mathrm{~m} \times$ $7 \mathrm{~m}$ (14 ft $\times 23 \mathrm{ft}$ ) NASA Langley V/STOL wind tunnel. The parameters investigated during these tests included tower height-to-diameter ratio (H/D), vane angle, and turbine wakevortex interaction.

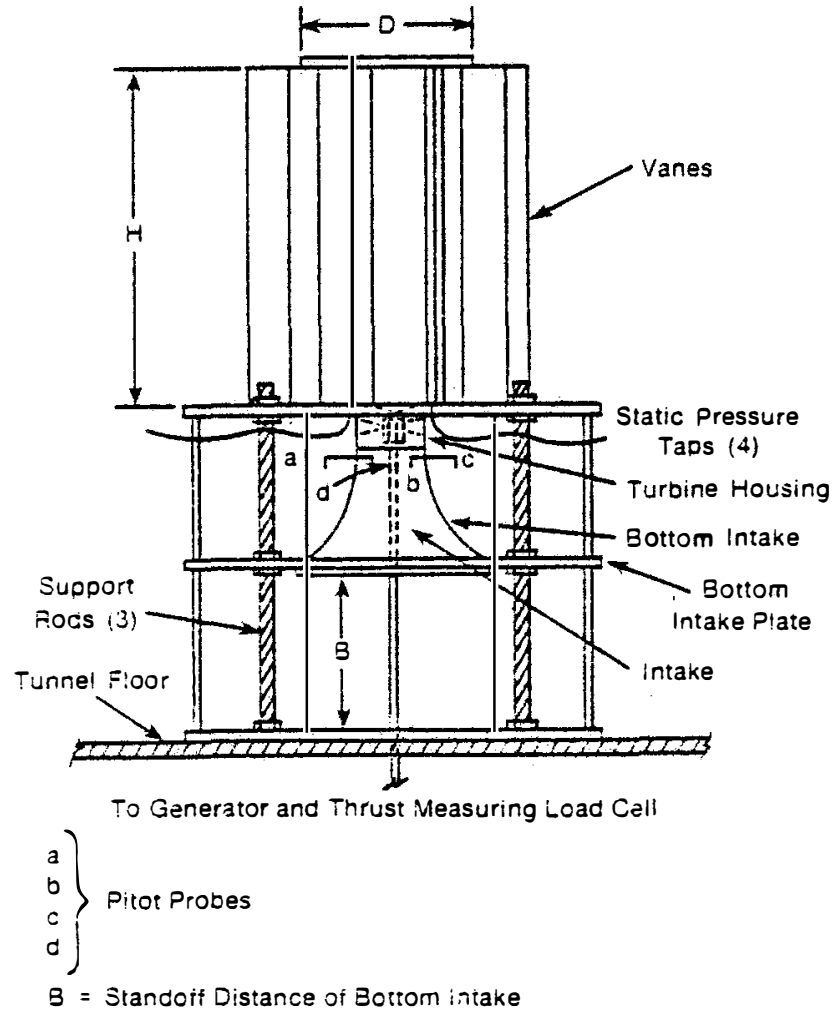

Figure 5. Experimental Setup. Side-View of Yen Multi-Vane TWES Model [from Ref. 3]

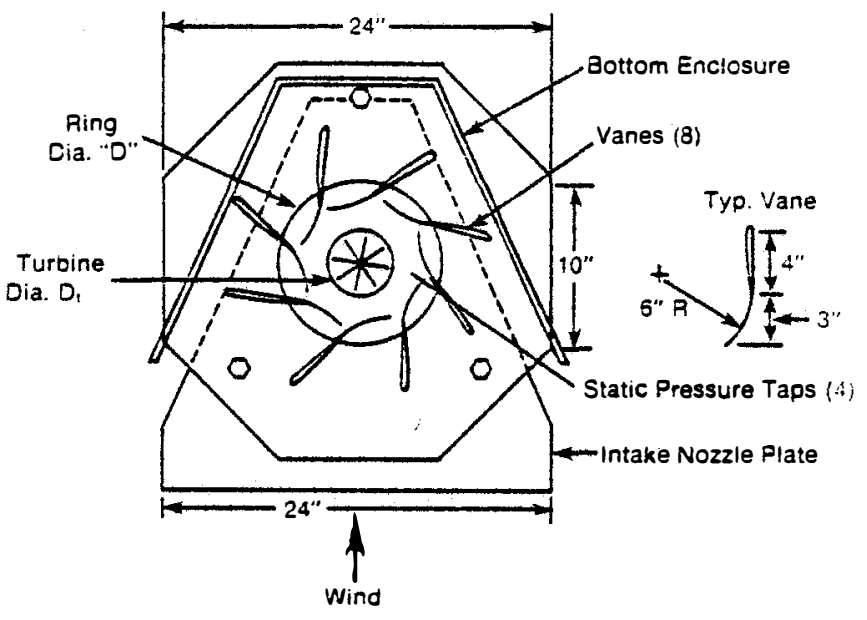

Figure 6. Experimental Setup, Top-Yiew of Yen Multi-yane TWES Model [from Ref. 3]

Note that the turbine intake for both sets of multi-vane tower tests consisted of a ram air inlet, referred to as the bottom enclosure in Figure 6 , with a cross-sectional area at least as large as the tower cross-sectional area. In many cases the ram air intake was simnificantly larger than the TiNES model tower, being at least $0.155 \mathrm{~m}^{2}\left(1.67 \mathrm{ft}^{2}\right)$ for the Grumman wind tunnel tests and $0.34 \mathrm{~m}^{2}\left(3.6 \mathrm{ft}^{2}\right)$ for the Langley V/STOL wind tunnel tests. The models ranged in cross-sectional area from 0.13 to $0.77 \mathrm{~m}^{2}$ (1.4 to $\left.8.3 \mathrm{ft}^{2}\right)$ with the peak power coefficients, being found with a tower crosssectional of $0.13 \mathrm{~m}^{2}\left(1.4 \mathrm{ft}^{2}\right)$. Thus a reduction by at least $50 \%$ of the peak power coefficients reported by $Y$ en for the multi-vane tower configuration appears to be warranted. Although this reduction has not been incorporated in the results reported by the present paper, it should be considered when gauging the potential of the TiNES as a WECS. Also, note that the size of the ram air intake significantly impacted wind tunnel blockage effects for the Grumman ivind tunnel tests. This is apparent in the marked reduction in peais

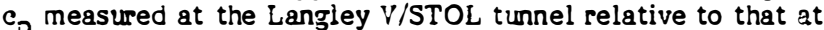
the Grumman wind tunnel, despite the increased size of the ram air intake.

\section{The New York Universitv Studv (Miller et al.)}

Experimental research on the TWES has jeen performed $y$ Viller et al. [ $\sharp$ at New York University (NYU) under joint support by the Neiv York State Energy Research and Development Authority (NYSERDA) and the Power Authority of the State of New York (DASNY). The study included the testing and optimization of a $3.01 \mathrm{~m}$ (2 ft) dianeter wino tunnel model and atmospreric testing oi a $6.1 \mathrm{~m}$ (25 it) diameter prototype.

TiVES models $0.01 \mathrm{~m}(2 \mathrm{it})$ in diameter and $1.22 \mathrm{~m}(4 \mathrm{t} t)$ in

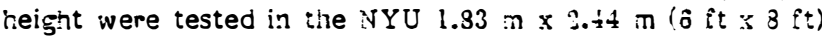
wind tunnel. Both the soiral and fixed inulti-vane configurations shown in Eigures $i$ and 8, respectively, vere emploved. However, as can je seen in हैigure 7 , the iurbine was significantly misaligned with the vortex core and most likely ivas eff ectively destroying any vortex generated within the tower. Thus, aithougn WYU found the spiral tower Jerfornance to be only is-jt's of the multi-vane cower jerformance, this result is suspect cue to injucicious glacement of the bellmouth inlet in che soiral tower jottom. this problem did not oceur in the testing of the multi-vane soniiguration.

The at:mospheric testing oi the 3.1 n (20 it) diameter nulti- 


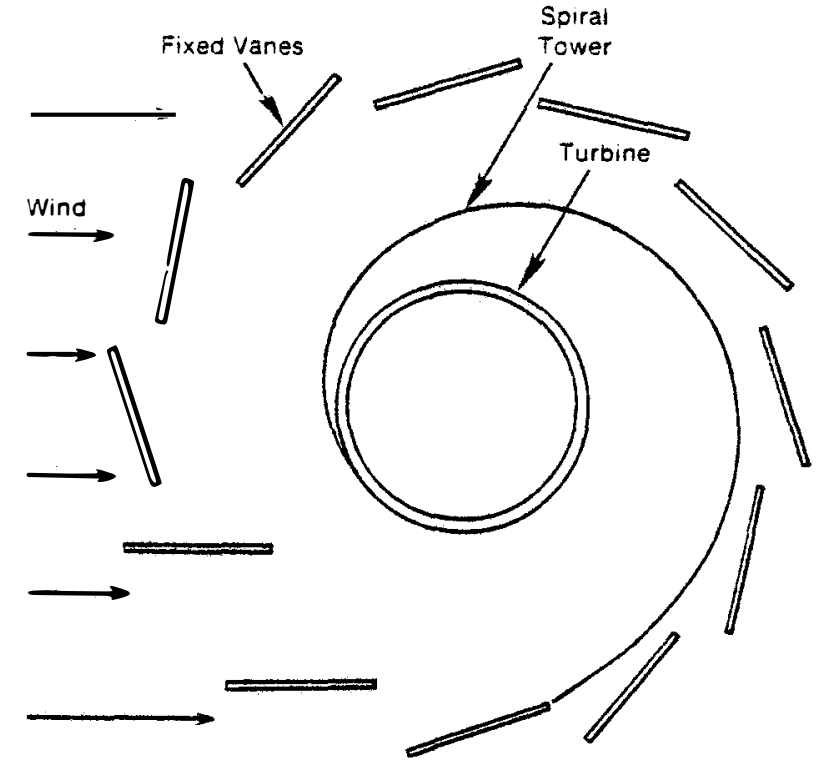

Figure 7. Top View of Spiral Tower Model Tested by NYU [from Ref. 4]

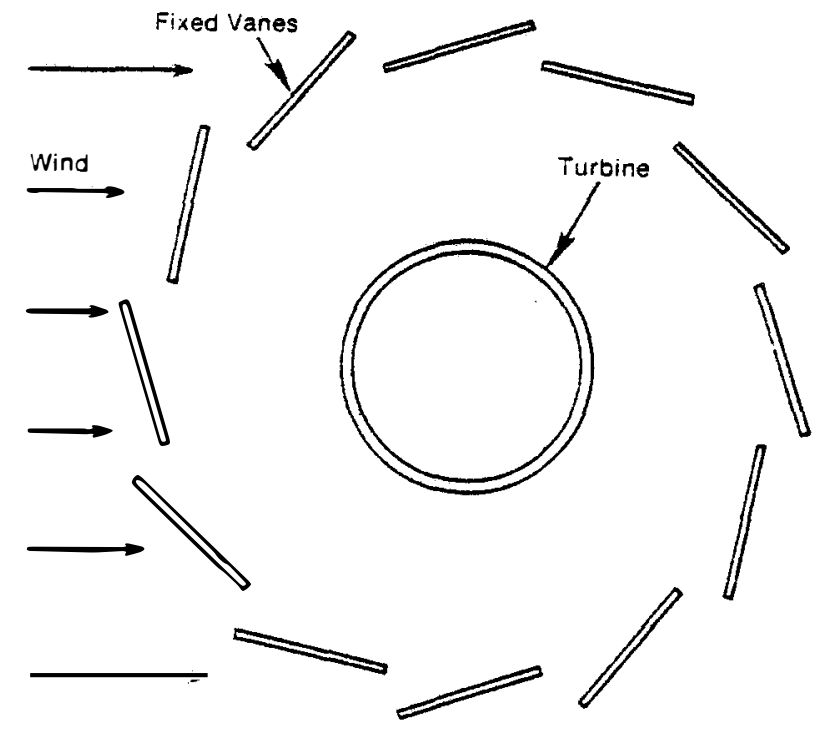

Figure 8. Top View of Fixed Multi-Vane Tower Model Tested by NYU [from Ref. 4]

vane TiNES by NYU 'vas intended to contirn the vind tunnel test resuits. In addition, the eif ect of increasing system size. i.e.. increasing tower diameter at constant height to diameter ratio and turoine to tower diameter ratio, on T'NES periormance : vas also investizated. The tests were imited in scope and therefore inconclusive although the results tended to gualitatively support the wind tunnel test resul ts.

\section{The Experiments of Windrich. Henze. and Ericke}

in experimental investigation of the T'NES nas aiso been undertaken by ivindrich. Henze. and Fricke [ji. The T'NES model tested utilized a spiral confizuration based upon Euuation (3) with $\alpha=0.1$ and $r_{0}=0.1 \mathrm{in}$ (3.94 in), this sroviding a tighter soirsl than used by $Y$ en. Vleasureinents vere mace of the angential velocity distribution, $V_{n}$, the vortex circulation. $f$, and the vortex core dinneter, Availabie poiver was deduced from the measurements by

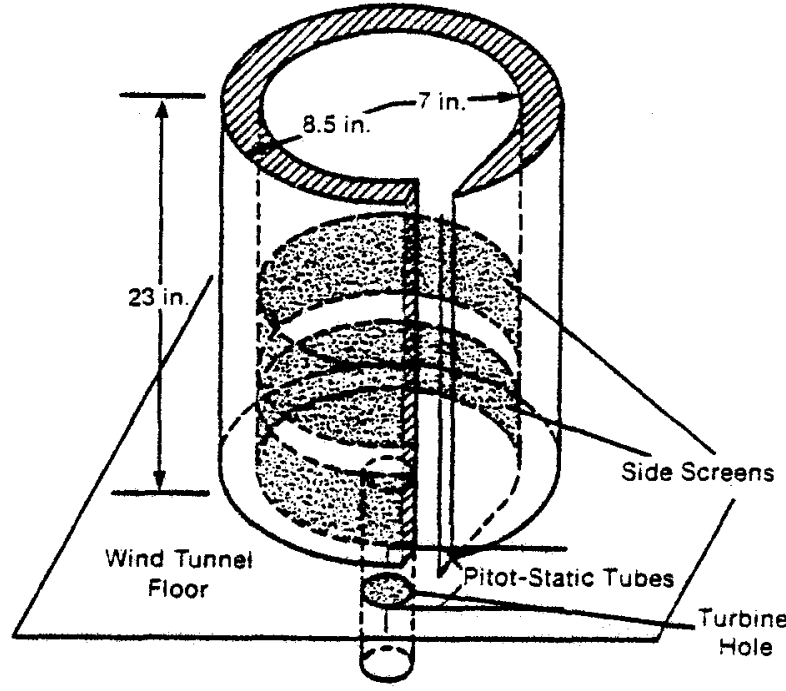

Figure 9. Sketch of a Circular Model [from Ref. 6]

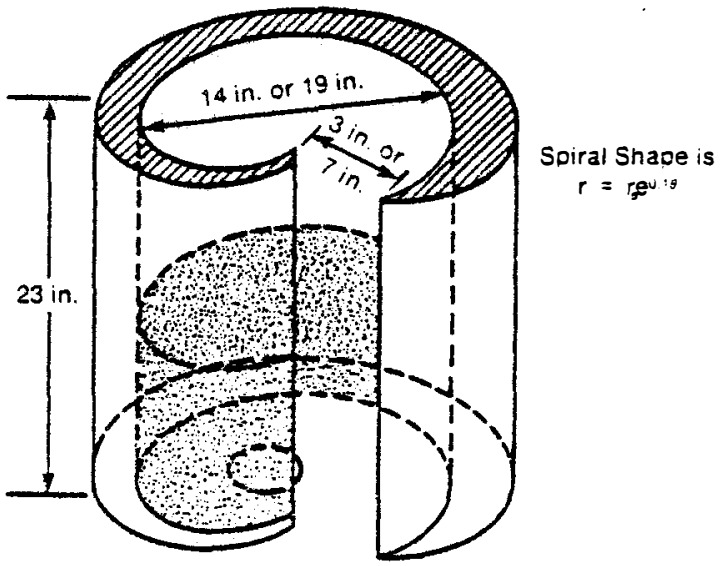

Figure 10. Sketch of a Spiral Model [from Ref. 6]

assuming a rectangular pressure distribution based on the maximum pressure cericit found at the vortex core and a diameter determined from the experiments. Thus, these experiments do not provide a quantitative assessment of TiNES potential. Howeyer, several tower height to ciameter ratios $(H / D)$ between $1 . \bar{s}$ and $4 . \bar{j}$ were used during the tests, and the relative effects of this oarameter on TiVES performance are readily ascertained.

\section{The Hsu and Ide Experiments,}

The experimental study by Hsu and ICe [6], also supported oy the U.S. Federal ifind Energy Program, was ocused on develooing methods ior intensifying the vortex generatej vithin the TWES iower. The iniensilication methods tesied included generating a radial inflow through the inner toiver wall, partial closing of the tower exist, and increasing the number of turns used for the soiral tower configuration. The soiral tower models were based on the configuration given by Equation (3) with $\alpha=0.10$ with tower jiameters (D) oi $0.30 \mathrm{in}$ $\left(14\right.$ in) and $9.48 \mathrm{~m}(19 \mathrm{in})$, corresoonding to $r_{0}=0.15 \mathrm{ir}(5.9 \mathrm{in})$ and $r_{0}=0.2 \mathrm{~m}(8 \mathrm{in})$. resoectively. Total towar uross-

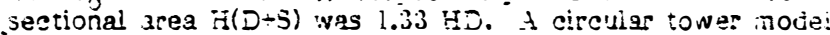
$(x=0) .36 m(1 \neq i n)$ in diameter ivas llso tested to nore closely sinulace the multi-vane tower conilizuration. Sketches of the models are shown in Figuros 3 and in. The radial innow was added to the vortex low through sice 
screens on the inner tower walls as shown in both figures. The inflow was generated by utilizing the dynamic pressure differential between the freestream and the vortex at the inner tower wall.

The models were tested in a $1.22 \mathrm{~m} \times 1.22 \mathrm{~m}$ ( $f \mathrm{ft} \times 4 \mathrm{ft}$ ) open cycle low speed wind tunnel at lowa State University with a maximum attainable wind speed of $7 \mathrm{~m} / \mathrm{s}$ ( $15.7 \mathrm{mph})$. No blockage corrections are included in the reported results. However, blockage effects may have been significant, especially for the interaction between the tunnel flow and the tower exit wake. All of the measurements were made with screen-simulated turbines either $10 \mathrm{~cm}(4$ in) or $5 \mathrm{~cm}(2$ in) in diameter.

\section{Results of the Experimental Studies}

Of primary importance in gauging the potential of the TiVES as a wind energy conversion system is determining both the maximum attainable performance and which geometric, operational, and environmental parameters significantly affect the performance of the TWES. The following sections summarize the effect of these parameters and the maximum power coefificients found in the experimental studies of Yen $[2,3]$, Miller at al. [4], Nindrich, Henze, and Fricke [5], and Hsu and Ide [a]. Results are presented, and correlated when appropriate, for all three T'WES tower configurations tested, i.e., spiral, circular, and multi-vane.

\section{Tower Height-to-Diameter Ratio (H/D)}

The experiments by Yen showed that for constant turbine-totower diameter ratio $\left(D_{t^{\prime}} D\right)$, the T'WES power coeificient decreases with increasing tower height-to-diameter ratio (H/D) for both the spiral and the multi-vane tower configurations. This relationship was confirmed by Nindrich et al with the spiral tower mooel, and a similar result was obtained by viller et al. for the multi-vane tower model. A plot of maximum or peak power coeificient ( $c_{0}$ max $)$ versus $\mathrm{H} / \mathrm{D}$ for $D_{\mathrm{t}} / \mathrm{D}=0.3$ based on the Yen results obtanned for the spiral tower model with screen-simulated turbines is shown in Figure 11 . These results indicate that $c$ is inversely proportional to $H / D$ within the tested range of $\mathrm{H} / \mathrm{D}=2.1$ to $\mathrm{H} / \mathrm{J}=4.2$. The ranges of $H / D$ tested by Yen with the multivane tower and by ivindrich et al. with the spiral tower were ! to 6 and 1.5 to 4.5 , respectively.

\section{Turbine-to-Tower Diameter Ratio $\left(D_{+}^{\prime} D\right)$}

The power coefficient $\left(c_{p}\right)$ ivas found by Yen to increase with increasing turoine-to-tower diameter ratio $\left(D_{t} / D\right)$ for the soirgl tower nodel A plot of the Yen results for $c_{\text {, }}$ as a function of $D_{t} / D$ with $H / D=2.1$ and screen=simulated turbines is shown in Figure 12. Based on these results, $C_{J, m_{3 x}}$ is proportional to $D_{t} / D$ within the tested range of $D_{t}, D=0.1$ to $D_{t} D=0.3$. Measurements made by Yen with a jladed turjine showed a simiiar effect with $D_{t} / D$ varied from 0.2 to $0 . \dot{1}$. Tests of the circular tower modei by Hsu and Ide corrcborated this resuit as $c_{\text {p }}$ was found to be higher for $D_{t^{\prime}} D=0.21$ than for $D_{t} / D=0.105$. The increase in $c_{s}$ with increasing $D_{t} / D$ indicates that the vortex core diameters exceeded the turbine diameters ior joth sets of experiments.

\section{System Size}

3oth Yen and Hsu and ide achieved an improvement in spiral iower jertormance by increasing the nodei size while Keeping $\mathrm{H} / \mathrm{D}$ and $\mathrm{D}_{-} / \mathrm{D}$ constant. For $\mathrm{D}_{,}, \mathrm{D}=0.3$ and $\mathrm{H} / \mathrm{D}=$ $2.1, y$ en obtained an increase in $c_{n}$. of of 32 并 from 0.033 to 0.06 using the soiral tower nodel vith screen-si:nulated turoines. However, both the Yen and the Hsu and Ice tests :vere limited to only tivo different tower sizes and therefore cannot be extrapolated to the tower sizes necessary for full scale Tives. Furthermore, the smail sizes of the morieis

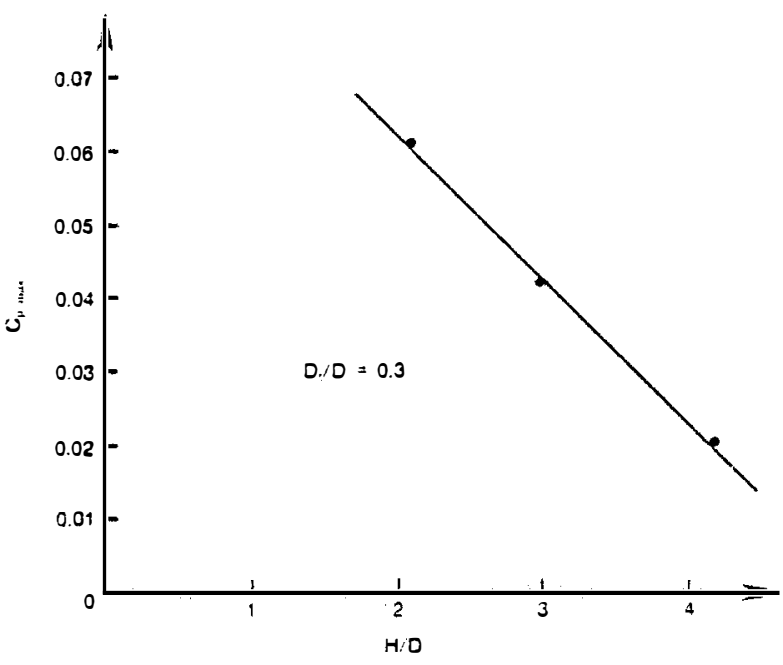

Figure 11. Variation of $C_{D . m p r}$ with Tower Height to Diameter

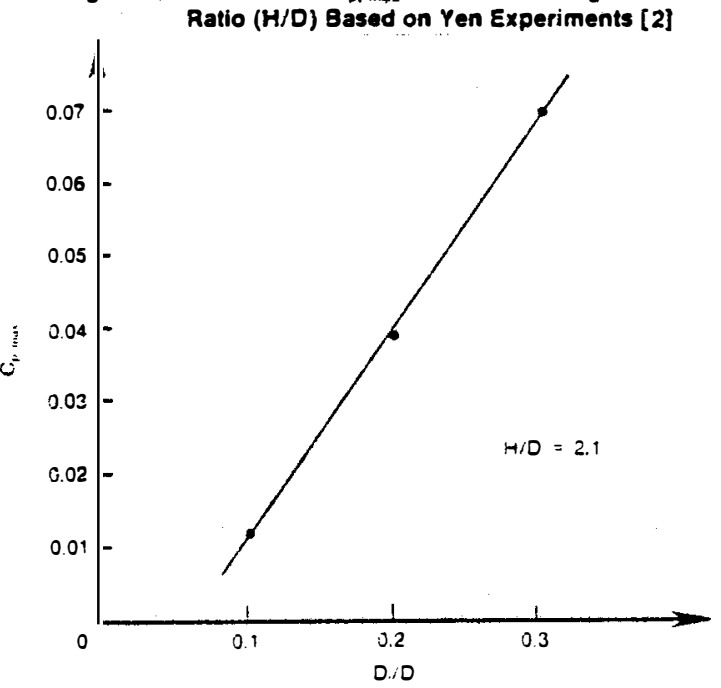

Figure 12. Variation of $C_{p . \text { max }}$ with Turbine to Tower Diameter Ratio $(D, / D)$ Based on Yen Experiments [2]

tested provided Reynolds numbers limited to the laminar and iransition ranges which also preciudes extrapolation to ivلll scale TWES in the turbulent range. For the multi-vane tower configuration, Miller et al. iound no significant per formance improvement between the $0.31 \mathrm{~m}(2 \mathrm{ft})$ diameter wind tunnel model and the $6.1 \mathrm{~m}(20 \mathrm{ft}$ ) prototype, aithough wind shear effects on the prototype due to the atmospheric boundary layer may have mitiggted any size eifects between the two measurements. Thus these resul ts do not provice conciusive proof regarding any benericial size eifects on TiVES performance.

\section{Turoine Waka-Vortax Interacticn}

For both the spiral and multi-vane tower configurations. the $Y$ en results indicate that the turoine wake can udiverseiy sif ect vortex strength and availeble vortex power. Ecr the spiraj tower model $:$ vith the bla:ted turbine, the naximum Dower coerficient iound by $Y$ en ivas 0.18 for $D . ' D=1 . t$ and HiD $=$ 2.i. However. the is vaiues were based joon aporoximate neasurements of apparent availabie vortzx - power and the maximum $c_{2}$ based upon turbine staft po:ver output was 0.045 or $4.5 \%$. Because the turjine vas axtrenei. crude and ineffieient, joerating it 3 deduced otîjieney oi $25 \%$ for peak $c_{p}$ conditions, the turbine wake sontuined 
significant angular momentum coincident with the circulation of the vartex. Thus the potentially adverse effects of axial turbine wake flow may have been mitigated by a rotational component in the wake. in comparison, the maximum power coefficient, based on available vortex power, measured by Yen for the spiral tower model with screen simulated turbines providing axial wake now, was 0.06 for $D_{t} / D=0.3$ and $H / D=$ 2.1.

For the multi-vane tower model with a bladed turbine, Yen found that power coetficients obtained with coincident wake and vortex rotation exceeded by more than $25 \%$ those obtained with opposite wake and vortex rotation. Also note that both the Yen multi-vane tower tests and the Hsu and Ide tests obtained generally decreasing power coeificients with increasing freestream wind velocity $\left(\mathrm{V}_{\infty}\right)$. An explanation for this result could be increasingly destructive effects of a fixed diameter turbine wake on increasingly smaller diameter vortex cores produced by the higher freestream wind velocities.

Thus any turbine wake component other than rotation coincident with the vortex circulation apparently has an adverse effect on power available to the turbine. This result is important as high efficiency turbines characteristically have axial wake lows and thus high effficiency and low ef ficiency turbines may provide essentially equivalent power coefficients based on turbine shaft power output.

\section{Partial Closure of the Tower Exit}

Hsu and Ide obtained a significant increase in cy by partially closing the exit of the spical TWES tower. This presumably further contined and stabilized the vortex. As shown in Figure 13 , for the $0.36 \mathrm{~m}$ (14 in) diameter spiral tower model, $c_{?}$ was maximized by limiting the exit opening to $0.6 \mathrm{D}$.

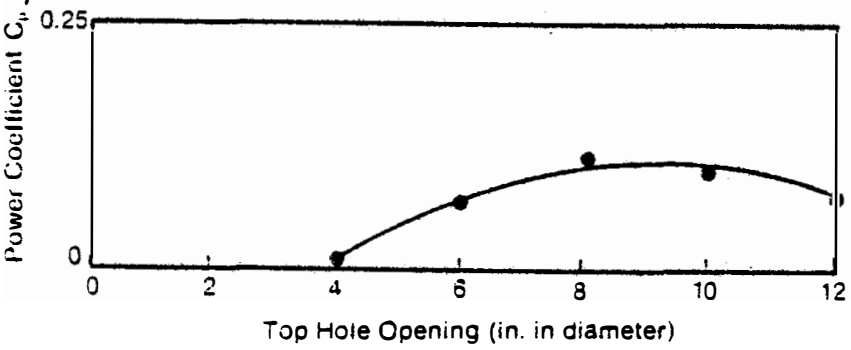

Figure 13. Power Efficiency vs. Top Hole Opening Size for the $0.36 \mathrm{~m}$ (14 in) in Diameter Spiral Model with No Radial Inflow Supply [from Ref. 6]

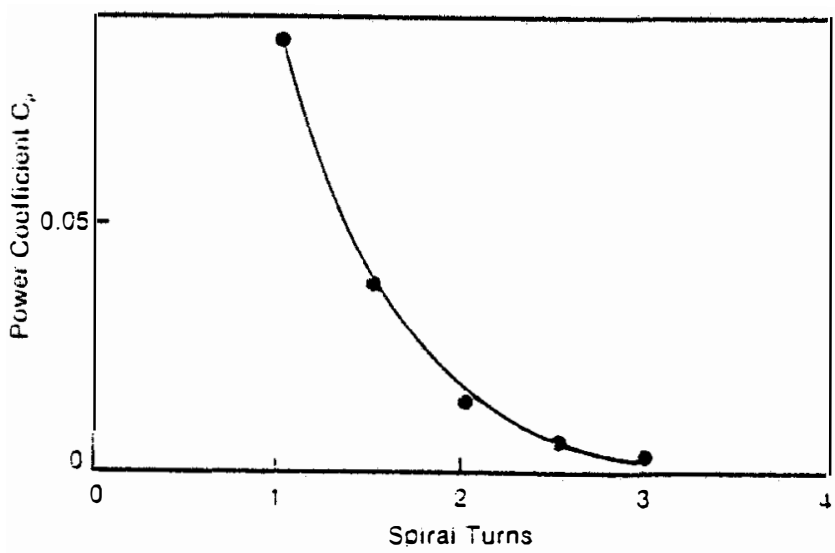

Figure 14. Power Efficiency vs. Spiral Turns for the $0.36 \mathrm{~m}$ (14 in) in Inner Diameter Spiral Model with No Radial Inflow Supply [from Ref. 6]
The corresponding increase in $c_{0}$ exceeded 50\%. All subsequent tests of the spiral tower model by Hsu and Ide incorporated this finding. For the $0.48 \mathrm{~m}$ ( $19 \mathrm{in}$ ) spiral tower model, Hsu and ide chose to close of $f$ exit how trom the inlet region of the tower.

\section{Number of Spiral Tower Tums}

Hsu and Ide giso attempted to increase $c_{\text {by }}$ bycreasing the number of turns for the spiral tower madel. However, as an be seen in Figure 14, adding turns to the model adversely aif eeted $c_{p}$, with the maximum $c_{\text {f }}$ found with two turns being only $\sim 15 \%$ of that found with orfe turn. These low $c_{p}$ were apparently due to increased friction losses and now separation. Based on this finding, the optimum number of turns for the spiral tower configuration is approximately one.

\section{Radial Inflow/Vortex Intensification}

Hsu and Ide found that performance can be enhanced by a radial intlow through screens on the inner wall of the TiVES as shown in Figures 9 and 10. The vortex intensifying inflow was zenerated by the dynamic pressure head bet'veen the ireestream and the vortex at the inner tower wall. For the circular tower model maximum $c_{0}$ was increased approximately $80 \%$ by adding the radial inflow to the bottom third of the tower. For the spiral tower models, the increase was only 15 to $30 \%$ with an optimum side screen height of $0.1 \mathrm{H}$. The lower increase found with the spiral configuration would be expected as the spiral shape naturally induces radial innlow due to cecreasing radius of curvature and thus addition of artificially induced radial inflow is less effective.

\section{Yane Angle}

The Yen multi-vane tower models utilized $0.1 \mathrm{~m}$ ( 4 in) inflexible, uncambered, symmetrical vanes with $0.08 \mathrm{~m}$ ( $3 \mathrm{in})$ Ilexible extension naps for a total vane width of $0.18 \mathrm{~A}$ (7 in). Similarly, the vanes employed by Miller et al. in the NYU study were inflexible. uncambered louvers un to $0.13 \mathrm{~m}(7 \mathrm{in})$ in width. Vane angle for both studies was defined as the angle be the straight section and the tangent of the tower circumference. Best performance resul is vere obtained by Yen for small vane angles $\left(\sim 30^{*}\right)$ with concave inward inges

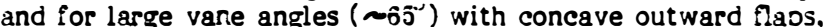
with the large vane angle periormance being slightly greater. Willer et al. found optimum performance at the smail vane angle of approximately $20^{\circ}$ and no optimum tor the large vane angles. The differences between the $Y$ en and villler et il. results are most jrobably due to the flexibie extension flaps added to the $Y$ en models.

\section{The Chimnev Effect}

During testing of the multi-vane tower by iniller et al., the tower was wrapped to measure the contribution of the chimney aff ect on TiVES performance. The chimney eif ect is an upward Kow througn the tower generated by the viscous airflow across the too of the tower. Hijler er al. found that a ivrapped multi-vane tower utilizing lie chimrey eifect proviced a jower output nearly equivalent to that of the multi-vane T'VES tower with optimum vane angle. The chimney arfect pressure arod, nearly constant across the tow $\in$ bottom, vas approximately equal to the maximum pressure top found in the vortex core of the unwr3oceci tower. Thus for the multi-vane tower contiguration, :he vortex tow may only minimaily augment the po'ver orovideri by the cinimney eiferr.

\section{Taximum ?ower Coefficiant3}

The naxilnum or peak power coerficients, jetermined experimentally by Y en [a,j], VIiller 3 al. [t], and Hsu and ide if for the variols tower contigurations. are shown in 


\begin{tabular}{|c|c|c|c|c|c|c|c|c|}
\hline & tower shape & turbine & radial inflow & $\mathrm{D}(\mathrm{m})$ & $\mathrm{H} / \mathrm{D}$ & $D_{t^{\prime}} D$ & $c_{\mathfrak{?}, \max ^{1}}$ & $\theta_{0, \max ^{2}}$ \\
\hline Yen & spiral & screens & no & 0.25 & 2.1 & 0.30 & 0.06 & 0.04 \\
\hline Yen & spiral & bladed & no & 0.25 & 2.1 & 0.40 & 0.18 & 0.12 \\
\hline Hsu and Ide & circular & screens & no & 0.36 & 1.6 & 0.29 & 0.08 & - \\
\hline Hsu and Ide & circular & screens & yes & 0.36 & 1.0 & 0.29 & 0.15 & - \\
\hline Hsu and Ide & spiral & screens & no & 0.48 & 1.2 & 0.21 & 0.22 & 0.16 \\
\hline Hsu and Ide & spiral & screens & yes & 0.48 & 1.2 & 0.21 & 0.26 & 0.19 \\
\hline Yen ${ }^{3}$ & multi-vane & bladed & no & 0.25 & 2.0 & 0.40 & 0.11 & - \\
\hline Yent & multi-vane & bladed & no & 0.51 & 2.0 & 0.33 & 0.08 & - \\
\hline Miller et al. & multi-vane & bladed & no & 0.25 & 2.0 & 0.40 & 0.027 & - \\
\hline
\end{tabular}

Table 1. Vaximum TWES Power Coefficients-Experimental Results of Yen $[2,3]$, .Hiller et al. [4, and Hsu and Ide [6]

Table 1. The peak values based on both the tower areas HD and $H(D+S)$ are presented for the spiral tower. The Yen results for the multi-vane tower are derived from the maximum average $\Delta p$ ineasured across the turbine. The tower and turbine dimensions for which each $c_{p, \max }$ ivas found are also shown in Table 1.

The discrepancies between the respective tests of each tower configuration are largely attributable to differences in model geometries. Specifically the Hsu and Ide spiral tower models incorporated partial exit closure and smaller $H / D$ and $D_{t} / D$ ratios then those of Yen. Similarly, the Yen multi-vane tower results should be reduced to reflect the use of ram air inlets exceeding the tower cross-sectional areas. These differences, as well as potential size and wind tunnel jlockage effects. need to be factored into any comparisons of the resuits. When cone so the maximum power coefficients comoare favoraoly for each of the TivEs tower configurations.

The results oresented in Table l demonstrate the marked reduction in the power coetficients found with the multi-vane TiVES nodels, indicating that use of an omnidirectional tower Jesign may incur a significant performance penalty relative to unidirectional designs such as the spiral configuration. However. an omnicirectional tower design would be necessary to permit use of winds from all directions.

\section{TIEORETICAL ANALYSES OF THE TWES}

Several theoretical studies have attempted to analyze the performance attainable by the Tornado ivind Energy System. These include the numerical analysis by Ayad $[7,8]$ and the mathematical solutions derived by Yen [?], Milier et al. [H], Vindrich et al. $[5]$. Hsu and Ide $[6]$. Loth $[9,10]$, Hsu et al. [1]1, So [i] as improved by Johnston and Eaton [ 13$]$, Chen [1 4 , and Rangivaila and Hsu [ij]. Although many lacis sufficient experimental verification. some quantitative and nany qualitative results can be obtained from these enalytical nodeis.

\section{iumerical Analysis of the TivES}

The numerical analysis of Ayad [7,3] employed the unidirectional spiral tower sonfiguration on the assumption that it 'vould provide an uoper limit to the ootential periormance of the Jnnidirectional muiti-vane T'NES tower. The initial

i jased on :ower frontal area HO

$?$ based on totai soira! tower :mntal area $A(D+S)$

3 Grimman vind tunnel cesulis

1 Langiey V/STOL wind t!nnei resuit effort by Ayad was to establish the validity of the numerical model relative to experimental data. Comparisons with the data of $Y$ en [2], as shown in Figures 15 and 16 , indicated that the model is adequate for predicting mean flow values and performance for TiNES. The ensuing study by Ayad analyzed the effects of several geometric and environmental parameters on TWES performance. A unif orm axial turbine flow was assumed to enable calculation of power coefficients $\left(c_{p}\right)$. The results of the Ayad study of the TiWES are summarized below.

\section{Tower Height-to-Diameter Ratio (H/D)}

In agreement with the experimental resuls of Yen $[2,3]$, VIiller et al. [4], and ivindrich et al. [5], Ayad determined that increasing $H / D$ adverseiy affects TWES performance. is

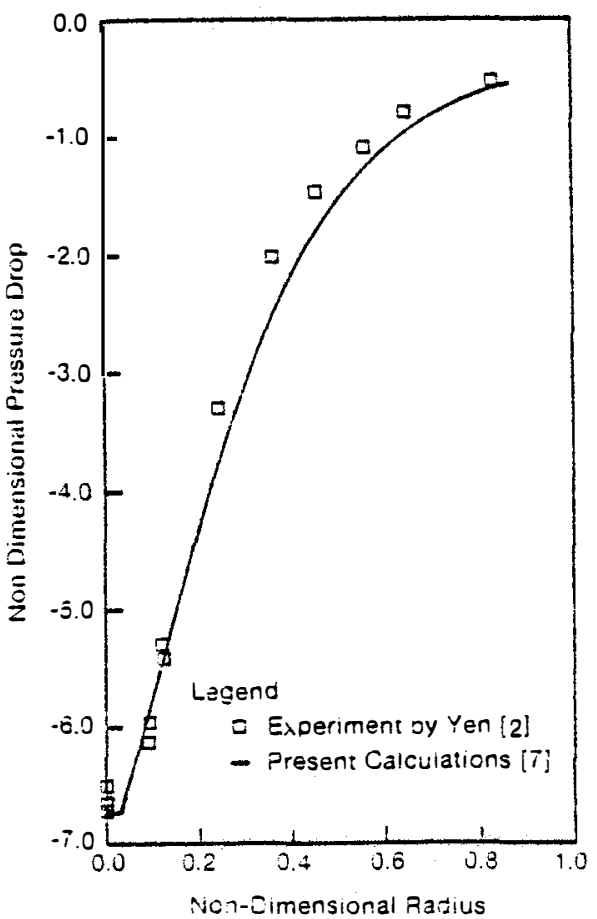

Figure 15. Radial Distributions of Pressure Drop at the Bottom of the Closed Sottom Tower, Values Normalized by $1 / 2\left(\rho \vee x^{2}\right)$ [from Ref. 7 ] 


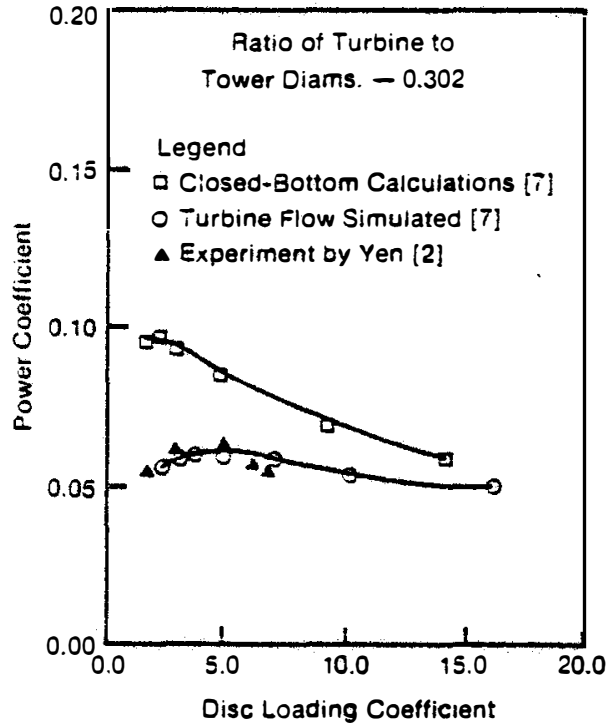

Figure 16. Comparison Between Power Coefficient Obtained for Closed Bottom Tower, Tower with Simulated Turbine Flow and Experiment by Yen[from Ref. 7]

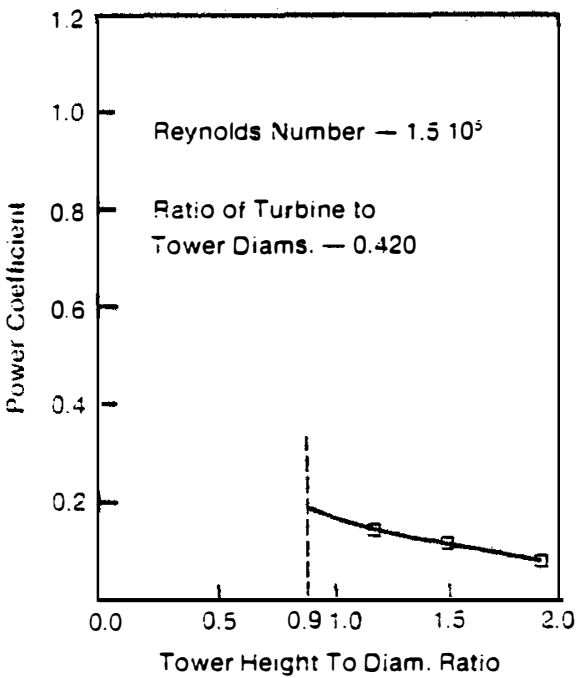

Figure 17. Variation of Power Coefficient with Tower Height-10-Diameter Ratio [from Ret. 8]

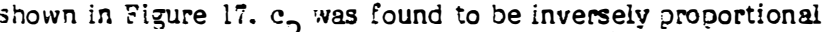
to $H / D$ ior the H/D range of 1 to 1.9. Yen [2] obtained the same resuit with the spiral tower for H/D > 2.1. Because TiVES vortex decay vould be assymetric, an H/D of 0.9 :vas estimated by Ayad to be the lower limit of validity for the symmerric model and $a$ nininum 3 iD of 1.0 was recommended for the TWES.

Turjine-to-Tower Diameter Ratio (D.D) and Turbine irake-iortex Interzction

Ayad found thet the variation of TiNES performance as a function of D.i'D was alosely related to the eifects oi tur jine vake-yortex interaction. is can be seen in Eigure 13. of based on the ciosed jottom vortex oressure distribution vas iound to continuously increase for $D_{t} i D<0.3$. However, the

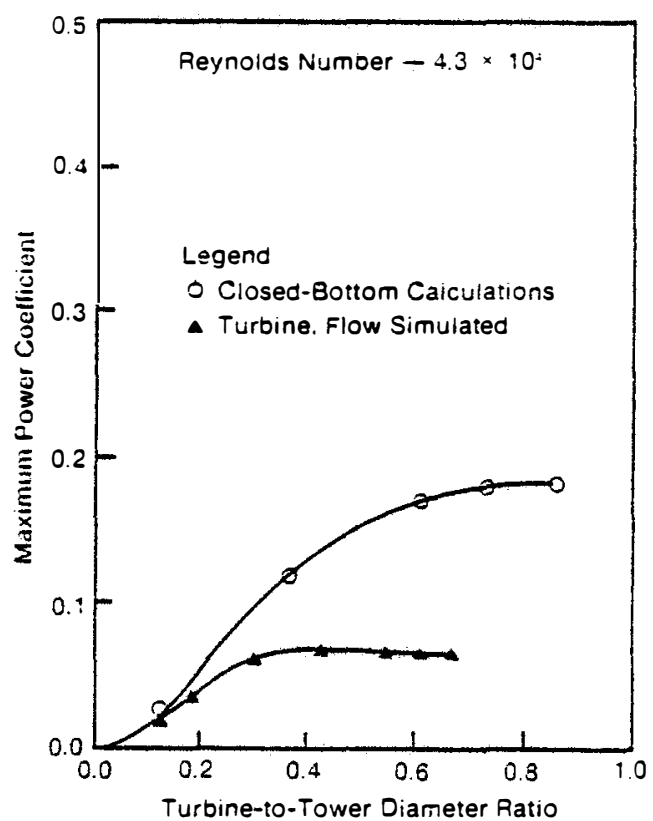

Figure 18. Comparison of Maximum Power Coefficients for a Simulated Turbine Flow and a Ciosed-Bottom Tower [from Ref. 7]

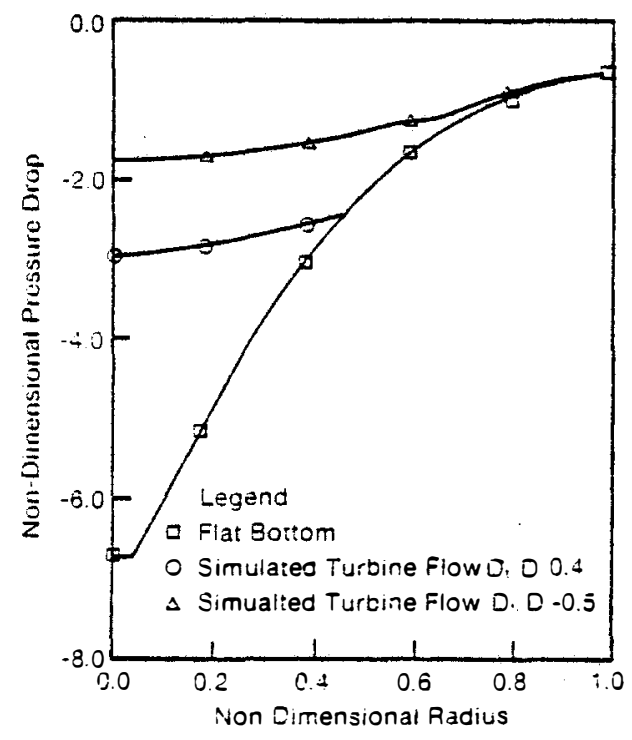

Figure 19. Comparison of the Radial Distribution of Pressure Drop in the Tower for the Case of a Ciosed Bottom Tower and Those with a Simulated Turbine Flow (values normalized by $1 / 2 V_{x^{*}}{ }^{\text {) }}$ [irom Ref. 7]

results indicate that with simulated turoine fow, a naximiln $c_{0}$ cecurs at 3 Do $/ D$ oi $\sim 0$.t For the assumed tower inle: and turbine rlow condition. The losses in o, relative to the closed bottom calculations are an eifect of the turbine :vake-1/orta: interaction. The turbine wake llow adversely aliects yortak strength causing a severely diminished pressure croo in the vortex core as shown in Figure 10. Note that the increase in $e_{p}$ with increasing $D_{z^{\prime}}$ D ior $D_{z^{\prime}}$ D $<0.4$ and the aciverse 


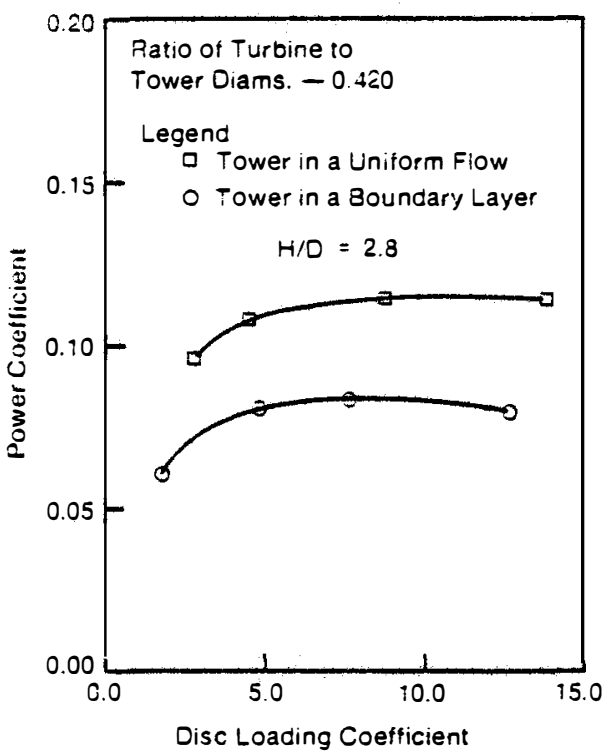

Figure 20. Effect of Atmospheric Boundary Layer on the Power Coefficient [trom Ref. 8]

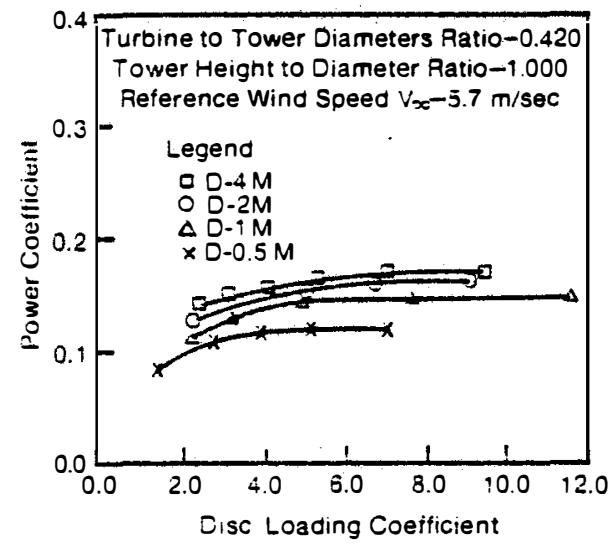

Figure 21. Effect of Systems Size on the Performance of Tornado-Type Wind Energy Systems [from Ref. 8]

efiects of turoine wake-vortex interaction were Cemonstrated experimentally by Yen $[2,3]$. Hsu and Ida [6] also experimentally verified increasing $c_{0}$ with increasing $D_{t} / D$. aibeit for $D_{t} / D<0.21$.

\section{Atmosoheric Bo'ndarv Laver Effects}

The experimental resuits obtained to date for the TiVES have been senerated in wind tunnels with uniform nlow. Ayad analyzed the potential eifects of wind shear, such as found in the atmospheric boundary layer, on TivES performance. Issuming a one-seventh power law bouncary layer with the ireestream wind velocity at the tower top equivalent to the unirorm freestream wind velocity, 1 yad calculated reductions in power of up to $23 \%$ in comparing the boundary layer results to those with unitorm flow. These results are shown in Eigure 30 and indicate that the strength of the vortex within the bottom region of the tower significantly sifects Tives performance. This ïnding is corroborated by the experiments of Isu and Ide [s] in which the radial inflow added near the tower jottom was found to be nost eifective. Yen [z] ziso is onvered consicerable boundary iayer effects during testing of the soiral ioiver mociel.

\section{Size Efferts}

Results obtained by Ayad indicate that with $H / D$ and $D_{t} / D$ held constant, the performance of small spiral Tives improves with increasing system size for $D<8 m(26.2 \mathrm{ft}$ ). Hcwever, as shown in Figure 21 the rate of increase diminishes as $D$ approaches the $8 \mathrm{~m}$ limit. While increasing tower diameter from $0.3 \mathrm{~m}$ ( $1.64 \mathrm{ft}$ ) to $1.0 \mathrm{~m}$ ( $3.28 \mathrm{ft}$ ) improves performance by $\sim 23 \%$, increases irom $2 \mathrm{~m}(6.6 \mathrm{ft})$ to $4 \mathrm{~m}$ (13.1 $\mathrm{ft})$ and from $4 \mathrm{~m}(13.1 \mathrm{ft})$ to $8 \mathrm{~m}(26.2 \mathrm{ft})$ only increase performance by $5 \%$ and $1 \%$, respectively. Thus, for the spiral tower configuration, power coefficients would apparently be independent of system size for tower diameters in excess of $8 \mathrm{~m}(26.2 \mathrm{ft})$.

\section{Haximum Power Coef ficient}

Based on a synthesis of the Ayad results, the predicted maximum power coefficient, $c$, for the TWES would be approximately 0.20 for $H / D=P$ and $D_{t} / D=0.4$. Note that the Ayad analysis did not include either partial closing of the tower exit or addition of radial inflow through an inner tower wall, both of which might increase this prediction.

\section{Mathematical Derivations oi TWES Performance}

The mathematical solutions for TiVES performance derived by Yen [2, Miller et al. [4, Windrich et al. [3], Hsu and Ide [6], Loth [9,10], Hsu et al [1]], So [12], Johnston and Eaton [13], Chen [14], and Rangwalla and Hsu [1]] are all dependent on several underlying assumptions, idealizations, and/or approximations. These include assumed tower inlet velocity profiles, laminar and/or radially unbounded vortex flow, and assumed vortex velocity profiles. Also the turbine wakevortex interaction is zenerally neglected as insignificant or insolvable. Many of these ideaiizations and assumptions, as well as insufficient experimental verification, severely limit the validity of TWES performance predictions obtained from these analytical models. However, several conclusions regarding TWES performance can be correlated betiveen model results.

\section{Tower Height-to-Diameter Ratio (H/D)}

Is with the previously discussed experimental and numerical studies of the TWES, the inverse relationship between $C_{3}$ and

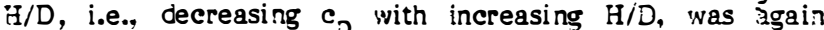
demonstrated by the modeis which incorporated analysis of this parameter.

\section{Turbine-to-Tower Diameter Ratio (D+iD)}

The analysis of Miller et al. for the milti-vane tower sbtained an optimum $D_{t} / D$ of 0.336 . This is close to the resuits obtained for the spiral configuration. The .:Iiller et al. experiments employed a $D_{t} / D$ oi $0.33[-4]$.

\section{Vane Angie}

The theoretical model develooed by iiller et al. also analyzed the eif fects of varying vane angie for the muiti-vane tower. The derivation inclujed the assumotion of simultaneous creation. confinement, and concentration of the vortex svithin the tower. The maximum jower coefficient vas found to be -1.20 for a vane or louver angle oi 4.5 .55 . However, the experimental work jy Miller et al. found simultaneous continement and concentration inieasible ; vith irsufficient confinement at $45.5^{\circ}$. For the experimentaliy determined optimum of $20^{\circ}$, the 1 iller et al nodel predicted a peak power coefficient oi $\sim 0.045$ vinich compares iayorajly witi the experimental resuit oi 0.027.

\section{Vortex Intensification}

Several of the analytical nodeis predict increased periormance by intensilication or strengthening of the 
vortex, thereby reducing the vortex core diameter. These predictions range up to a cubic increase in power coefficient with decreasing vortex core diameter. Vortex intensification was achieved experimentally by Hsu and Ide [6] with both the circular and the spiral tower configurations by adding radial inflow through an inner tower wall. However, an increase in the number of turns employed by the spiral tower had the opposite eifect of weakening the vortex.

\section{COST . INALYSIS OF THE TIES}

An approximate but very simple cost analysis of the TWES can be based uon the research results detailed in the previous sections. Here the analysis will employ the multivane tower configuration and use the performance and cost characteristics of the MOD-2 $2.5 \mathrm{KW}$ horizontal axis wind turbine as a baseline for comparison [16. Use of the MOD-2 characteristics zraphically contrasts the potential of the T'WES for cost effective wind energy conversion.

From a synthesis of the research performed on the TWES, a peak system power coefficient of 0.10 appears to be a reasonable expectation of potential TWES performance suitable for estimating a cost of energy. Optimistically a peak system $c_{5}$ of 0.20 might be attainable. In comparison the iNOD-2 has a jeak system $c_{p}$ of 0.375 [19. The MOD-2 and approximate TWES dimensions are shown in Table 2 with the TWES geometry based on $H / D=1$ and $D_{t} / D=0.35$. The effects of wind shear, due to differing mean tower heights, are incorporated in the TWES dimensions shown. Also included in the table are estimates of the total suriace area of the vanes comprising the tower. As the vanes would presumably be hoilow (or double-walled) and overlapping, the total surface area is assumed to be approximately twice that of a cylinder of equivalent height and tiameter, i.e.. $2 \times \pi$ HD. This surface area is used to estimate the construction cost of the tower. Note that due to the required vane overlap the actual surface area of a multi-vase T'WES tower may be significantly higher.

Construction of a T', $\mathrm{TES}$ tower would be similar to that of a large natural draft cooling tower. The least expensive construction technique would likely be slip-iormed concrete Eabricgtion. However, due to the large size of a $2.3 \mathrm{MW}$ TWES, a uniform cross-section, necessary for slip-forming, may not be feasible, and the slower more expensive technique of jump-forming, such as used for the cooling towers, may je required. All cost estimates presented below are based on slip-forming a concrete tower for the TWES. The original cost estimate by $Y$ en [2] for a concrete tower was $\$ 0.91 / \mathrm{m}^{2}$ $\left(\$ 3 / \mathrm{ft}^{2}\right)$ of tower surface area. Two sources who have been involved in the design and construction of large natural dratt cooling towers were contacted to corroborate this estimat? $[17,38]$. Written communication irom these sources provided the following:

T consider slip-formed concrete as a most appropriate construction technique for your application. it lends itself in particular to tall structures with a uniform cross section such as the fixed vertical airfoii towers. Full circle structural elements can be accommodated easily by proper design of the moving forms and a start/stop placing technique to provide a monolithic and high strength structure. The airioil sections might even be slipped as hollow members. An $8^{\prime \prime}$ wall is probably near the lower limit of acceptable thickness, but it would probably depend on the redundancy of the structural system. Sections as thin as $6^{* \prime}$ have been slipped. $\$ 3 / \mathrm{ft}^{2}$ seems low by a factor of perhaps 10 for 1979 costs of construction. Again, this depends on the final structural design and the height. Slip forming, being an extrusion process, becomes cheaper with height and consequent amortization of form fabrication costs over volume extruded. Permanent (metal) forms may also be reusable and thus further decrease costs." [i]]

"It would seem, by preliminary inspection of the sketches and model photos, that the airfoil sections could be slipped as hollow members. This technique could provide a basis for determining a very preliminary budget estimate opinion, and would require structural engineering verification as io vane wall thickness and reinforcing steel requirements. Twenty to thirty dollars per square foot for the sum of the vane surface area would provide an approximate budget estimate of the structure cost." [18]

Thus a conservative estimate of TiVES tower construction costs would appear to be $\$ 9.15 / \mathrm{m}^{2}\left(\$ 30 / \mathrm{ft}^{2}\right)$ in 1979 dollars. Cost estimates for the TiWES tower are shown in Table 2 for peak system power coefficients oi $7.05,0.10$, and 0.20. The estimated mature prociuct ( 100 th unit) turnkey cost of the HOD-2 updated to 1973 dollars. is shown for comparison [1\%. Cost of energy (COE) ior each system can be estimatec by using the equation:



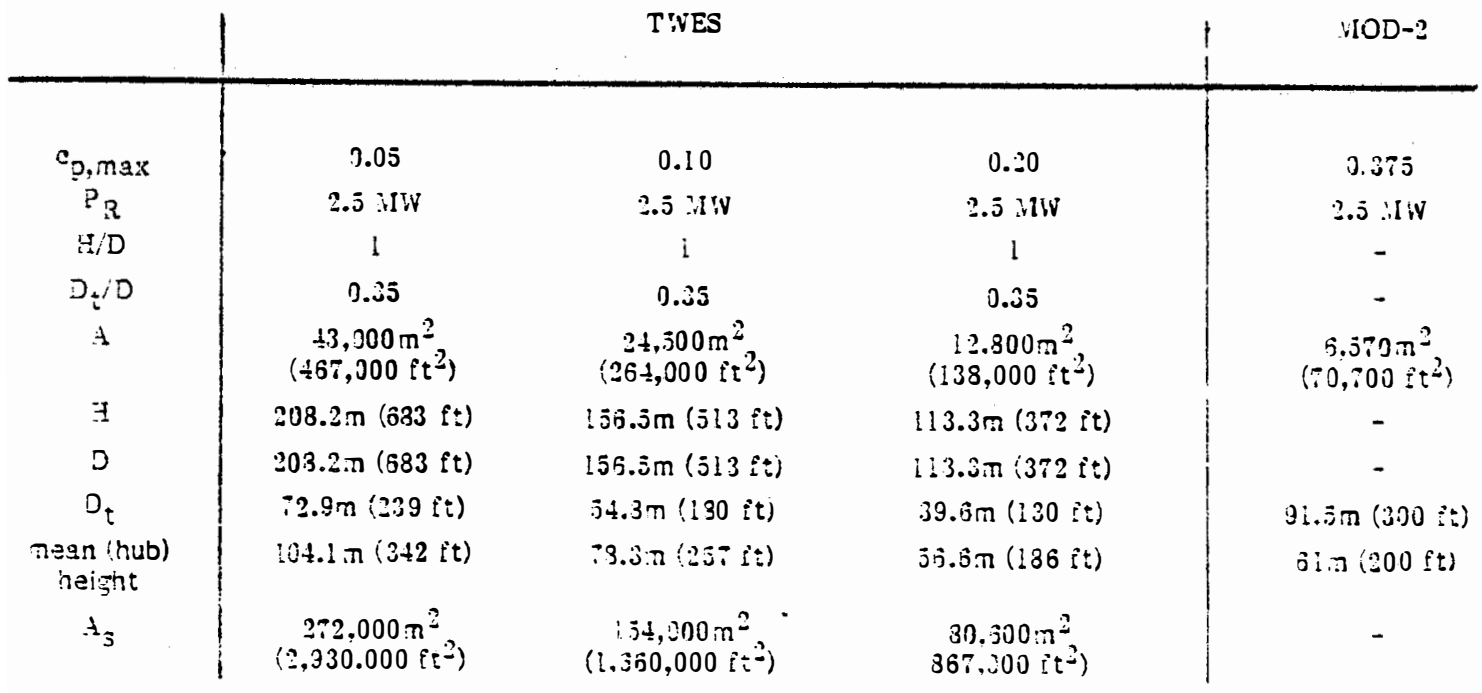

Table 2. TWES Dimensions (for s, s,max $=9.35 .0 .10$, and 0.20 ) Compared to $100-2$ Dimensions 


\begin{tabular}{|c|c|c|c|c|}
\hline & & TNES & & WOD-2 \\
\hline$c_{p, \text { max }}$ & 0.05 & 0.10 & 0.20 & 0.375 \\
\hline $\mathrm{P}_{\mathrm{R}}$ & $2.5 \mathrm{MW}$ & 2.5 . $1 W$ & $2.5 \mathrm{WW}$ & $2.5 \mathrm{MIW}$ \\
\hline $\begin{array}{l}\text { annual energy } \\
\text { output (kWh) }\end{array}$ & $9,750,000$ & $9,750,000$ & $9,750,000$ & $9,750,000$ \\
\hline capital cost & $\$ 87,900,000$ & $\$ 49,700,000$ & $\$ 26,000,000$ & $\$ 2,000,000$ \\
\hline $\begin{array}{c}\text { cost of energy } \\
\text { (COE) }\end{array}$ & $\$ 1.62 / \mathrm{kWh}$ & $\$ 0.91 / \mathrm{kWh}$ & $\$ 0.48 / \mathrm{kWh}$ & $\$ 0.04 / \mathrm{kWh}$ \\
\hline
\end{tabular}

Table 3. Comparison Between TWES Tower and MOD-2 Cost Estimates (1979 Dollars)

tssuming a sixed charge rate of $18 \%$ and an annual energy output for both systems of $0.445 \times 2500 \mathrm{~kW} \times 9760$ hours $=$ $9,750,000 \mathrm{kWh}$. The $0 . \$ 45$ or $\$ 4.5 \%$ apacity factor is predicted for the MOD-2 in a $6.3 \mathrm{~m} / \mathrm{s}$ (14 $\mathrm{mph}$ ) site [1에 and sho:vn in Table 3, the estimated COE in 1979 dollars $f \circ$ the TIVES, based upon the tower cost only, would be $\$ 1.62$ per $k W h$ for $c_{\text {max }}=0.05, \quad \$ 0.91$ per $k$ Wh for $c_{\text {max }}=0.10$, and 0.48 Pkwh for reflect tower costs only. These estimates compare very unfavorably with the estimated COE for the MOD-? in 1979 dollars of $\$ 0.04$ [1 14 . The COE of a TWES ;vould apparently exceed that of a MOD-2 by more then one order of magnitude. This result is corroborated by Kornreich, Kottler, and Jennings [19] when compared under equivalent perf ormance assumptions.

The tower cost would be the cost driver in a TWES installation. The balance of system costs would approximate those of the $110 D-2$ without the tower support. Although the smaller rotor 'Nould reduce the required gearing ratio and, to a lesser extent, the gearing costs, the rotor would presumably be a cross between a many bladed gas turbine and a wind turbine and therefore would be more expensive on a $\$$ /unit sivept area basis. Yen [2] estimates the per unit swept area cost of the T'NES rotor to be an order of magnitude freater than that oi a 1 INW wind turbine. The generator should cost approximately the same as an equivalently sized generator for a conventional sind turbine. Thus, the balance of system costs couid apparently be limited to 5 to $10 \%$ of the tower cost and would therefore have a much lesser impact on COE. Again this result is corroborated by Kornreicn, Kottler, and Jennings [19].

\section{SUMMARY AND CONCLUSIONS}

Over the past few vears an extensive body of knowledge has been developed on the potentiai of the Tornado Wind Energy System for cost eifective wind energy conversion. Research and development has progressed to the point where several conclusions can be formulated including:

- The TrVES apparently suffers severe physical limitations precluding performance at cost competitive powe: coefficients. Prospects for attaining power coerficients significantly above 0.20 with practical tower designs are not promising. A power coefficient approaching $\mathbf{2 . 0}$ wouid be needed to be cost competitive.

- Given the pertormance levels demonstrated to date the cost of energy (COE) for a TivEs would exceed that estimated for the HOD-? by more than one order of ragnitude. Prospects for acnieving a TiVES COE si-gnificantly less than 5i.50/kiVh (1979 dollars) also are rot promising.

o The Tornaco ivind Energy System toes not show any sibstantial promise of improving on either the pertornance or cost of energy attainable by a conventional horizcirtal or vertical axis wind turbine.

\section{REFERENCES}

1. Yen, J.T., "Tornado-type Wind Energy Systems," Proceedings of the 10th Intersocietv Energy Conversion Engineering Conierence. September 1975, pp. 987-994.

2. Yen, J.T." "Tornado-Type Wind Energy System," RE-57l, March 1979 (Revised April 1980). Grumman Aerospace Corp., Research and Development Center, Bethpaze, NY.

3. Yen, J.T., 'Investigations of the Tornado Wind Energy Systems," SERI/TR-11052-1, June 1982, Grumman derospace Corp., Research and Development Center, Bethpage, NY.

4. Miller, G., Hoffert, M., Corren, D., Hseih, W., and Volk, T., "The Tornado ivind Energy Conversion (TWECS) Evaluation Program at New York University, NYU/DAS 3115, July 1981, New York University, New York, NY (to be published by New York State Energy Research and Development Authority, Albany, NY).

5. Wincrici, J., Henze, B., and Frick, J., "Experimental and Theoretical Study of the Tornado Type Wind Energy System (TWES)," Proceedings of the International Colloaueum on wind Energy, British ivind Energy Association, 1981 .

6. Hsu, C.T. and Ide, H., "Eff ect oi Radial Inflow on Vortex Intensification for a Tornado-Type iVind Turbine," ISU-ERI-Ames 83073, Sept. 1982, Iowa State University, Ames, Iowa.

7. Ayad, S.S., "A Numerical vodel for the Flow Within the Tower of a Tornado-type :Vind Energy System." Journal of Solar Energy Engineering, Vol. 103, No. 4, Nov. 1381, 0. 299-305.

3. Ayad, S.S., "A Parametric Study of Tornado-type Wind Energy Systems," Proceedings of the Jth Biennial vind Energy Conference and Workshoo. C.S. Departinent of

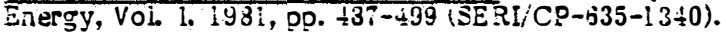

9. Loth, J.L., "Betz Type Limitations of Vortex VVind Vachines," Wind Engineering, Vol. 1. No. 3, 1977, pp. 169-13.5.

10. Loth, J.L., "Wiad Power Limitations Associated with Vortices," Joumal of Enersw, Vol. 2, No. 4, July-tug'sst 1978, pp. 216-202.

11. Hsu, C.T., Vellor, G.L., and Yen, J.T., "Some Flow dnalysis of a Tornado-type "Vind Turbine," Fluics Engineering in Auvanced Energy Sustems, Ameriean Society oì Dlechanical Engineers, 1973, ग9. 59-i!.

12. So. R.Vl.C.. "On Vertex "Vind Power," Journal Ji Eluids Engineering,

13. Jonnston, J.P. and Eaton, .J." On Vortex vind Poiver." Joumal of Fluics Engineering, V:Jl. !00, June :९ร:3, ?p. $252-254$.

14. When. J.M., "Vortex iffected by the Conizal Shace of Generator in Tornado-Tye Wind Energy System," Journal ai industrial Aerocivna nies, Vol. 3, !973, pp. 30i-313.

I.. Rangwala. A.A. and isu. C.T.. "Periornance and Flow tnalysis of vortex "Vind Power Turbines." isU-ERAines 33098, Det. 1982, :owa State University, A:nes, Loiva.

!s. "MOD-? inind Turbine System Concept and Proliminary Design Revort." DOE/NitSA 000?-80/2 (NAS.A CR-ij9689), Juy iar3, Joeing Engineering and Construction. 
Seatile. WA.

17. Private communication from A.C. Perkins, formerly of Fegles-Power Service Corp., letter dated August 5, 1980.

18. Private communication from $\Xi$. Yeager, VicePresident of Fegles-Power Service Corp., letter dated August $12,1980$.

19. Kornreich, T.R., Kottler J.., R.J., and Jennings, D.M., "Preliminary Tecinnical and Economic Evaluation of Vortex Extraction Devices," SERI/TR-3003-1, April 1980, JBF Scientific Corp., Arlington, VA. 